\begin{tabular}{|cc|}
\hline MASS SPECTROMETRY & RADICAL IONS \\
FRAGMENTATION & ELECTRON ENERGY \\
HYDROXY ACIDS & HYDROXY KETONES \\
ALDONIC ACIDS & ALDARIC ACIDS \\
LACTONES & KETOSES \\
\hline
\end{tabular}

Article included in $\underline{\mathrm{PhD} \text { thesis }}$

Organic Mass Spectrometry 6 (1972) 577-592

Link to publisher: DOI: 10.1002/oms.1210060514

\title{
A McLafferty type rearrangement of a trimethylsilyl group in silylated hydroxy carbonyl compounds
}

\author{
Göran Petersson \\ Department of Engineering Chemistry, \\ Chalmers University of Technology, Göteborg, Sweden \\ Related articles: \\ Mass spectrometry of hydroxy dicarboxylic acids as trimethylsilyl derivatives \\ Mass spectrometry of aldonic acids as trimethylsilyl derivatives
}




\begin{abstract}
A McLafferty-type rearrangement of a $\mathrm{Me}_{3} \mathrm{Si}$ group is demonstrated. Abundant rearrangement ions are formed for $\mathrm{Me}_{3} \mathrm{Si}$ derivatives of $\alpha, \beta$-dihydroxy carbonyl compounds. Data are given for a large number of hydroxy acids and hydroxy ketones including aldonic acids, aldaric acids, acyclic ketoses and hydroxy keto acids. A few branched lactones are also shown to rearrange.

The positive charge and the unpaired electron are extensively delocalized in the odd-electron rearrangement ions. Substituents at the $\alpha$-carbon atom which offer a favourable delocalization promote the rearrangement. Spectra of specifically methylated species reveal that migration over larger than six-membered rings occurs to some extent. An observed dependence of abundance on configuration is associated with steric strains in the transition state.
\end{abstract}

The rearrangement ions are of great diagnostic value in structural analysis. They are relatively more abundant at low electron energies and give rise to the base peak at $20 \mathrm{eV}$ for many compounds. Ions produced by competing conventional McLafferty rearrangement are less abundant.

\title{
Sammanfattning
}

En strukturspecifik omlagring av typ McLafferty påvisas för en $\mathrm{Me}_{3} \mathrm{Si}$-grupp vid masspektrometrisk fragmentering. Framträdande joner bildas för $\mathrm{Me}_{3} \mathrm{Si}$-derivat av $\alpha, \beta$-dihydroxikarbonylföreningar. Data ges för ett stort antal hydroxisyror och hydroxiketoner av typ aldonsyror, aldarsyror, acykliska ketoser och ketosyror. Omlagringen påvisas också för några grenade laktoner.

Den positiva laddningen och den oparade elektronen delokaliseras effektivt i de bildade radikaljonerna. Substituenter vid $\alpha$-kolatomen som ökar delokalisering främjar omlagringen. Spektra av specifikt metylerade ämnen visar att migrering i viss utsträckning sker över större ringar än den normala sexringen. Skillnader mellan diastereomerer kopplas till steriska spänningar i övergångstillståndet.

De studerade radikaljonerna har stort värde för strukturbestämning. De bildas relativt sett mer vid låg elektronenergi och ger upphov till bastoppen vid $20 \mathrm{eV}$ för många ämnen. Analoga joner från konkurrerande konventionell omlagring av väteatomer enligt McLafferty bildas i mindre grad. 


\title{
A McLafferty type rearrangement of a trimethylsilyl group in silylated hydroxy carbonyl compounds
}

\author{
Göran Petersson
}

\author{
Department of Engineering Chemistry, \\ Chalmers University of Technology, \\ Göteborg, Sweden
}

THE IMPORTANT McLafferty rearrangement ${ }^{1}$ refers to the specific migration of a $\gamma$-hydrogen atom to a functional group in an odd-electron ion, notably the molecular ion. In the first place it is associated with a carbonyl group as acceptor site and with the formation of a resonance stabilized odd-electron ion with concurrent loss of a neutral olefinic moiety.

It is generally believed ${ }^{1}$ that alkyl groups do not migrate in an analogous manner. In a recent investigation, ${ }^{2}$ however, it was concluded that a McLafferty-type rearrangement of a trimethylsilyl group occurs for trimethylsilyl (TMS) derivatives of aldonic and deoxyaldonic acids. Because of the mechanistic interest of the fragmentation and the wide use of TMS derivatives a more detailed study was made for different types of hydroxy carbonyl compounds.

The rearrangement for the compounds studied can be represented by analogy with the McLafferty rearrangement. This investigation is restricted to species with

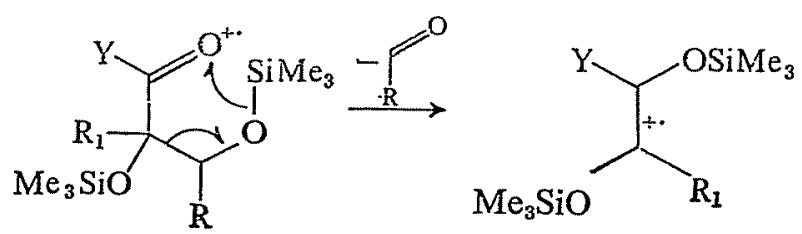

oxygen-linked TMS groups but a reported rearrangement for 4-trimethylsilylbutyrate $^{3}$ indicates that carbon-linked TMS groups rearrange as well. It has also been demonstrated ${ }^{4}$ that the TMS derivative of threonine with an $\alpha$-NHTMS group instead of the $\alpha$-OTMS group exhibits an abundant ion produced by the same type of fragmentation.

The rearrangement is discussed separately for the derivatives of the various types of compounds studied; hydroxy acids, acyclic ketoses, lactones and hydroxy keto acids. The evidence for the rearrangement and the structure of the resulting ion are discussed in some detail for the $m / e 292$ ion from 2,3-dihydroxy acids. Further aspects 


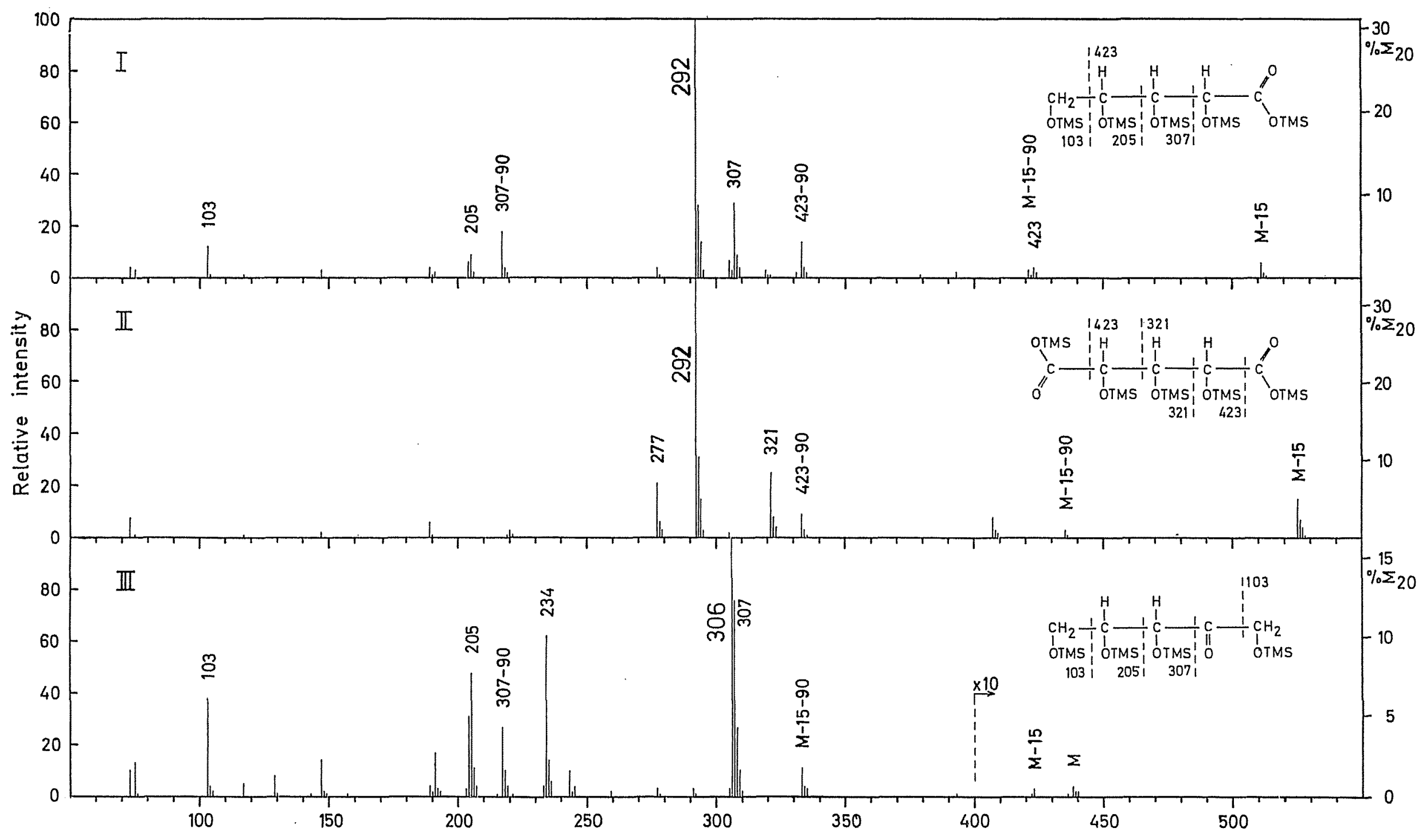

FIG. 1. Mass spectra at $20 \mathrm{eV}$ of the TMS derivatives of ribonic acid (I), ribaric acid (II) and ribulose (III). 
covered are; rearrangement ions of anomalously low intensity, the influence of different $\alpha$-substituents, the original position and the electronic nature of the migrating TMS group, configurational effects, and migrations over larger rings giving rise to ions with separate radical and ionic sites. The influence of the electron energy was also studied and the formation of ions from the competing conventional McLafferty rearrangement is discussed.

\section{2,3-Dihydroxy acids}

In accordance with the general fragmentation scheme above a prominent rearrangement for acids was observed only for those with a 2,3-dihydroxy acid structure. For acyclic acids without a branch at C-2 an ion of mass 292 is formed.

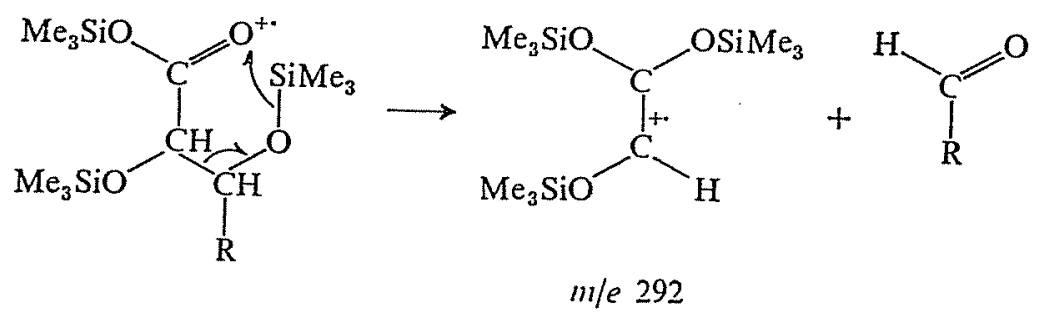

Illustrative spectra of a monocarboxylic (ribonic) and a dicarboxylic (ribaric) acid are represented in Fig. 1. The $m / e 292$ ion gives rise to the very intense base peak in both spectra emphasizing the significance of the rearrangement. For the Figures $20 \mathrm{eV}$ spectra were chosen, since the relative abundances of the rearrangement ions are higher at low electron energies.

Most of the other peaks are due to ions formed by carbon chain cleavages as indicated in the structural formulae. The eliminations of trimethylsilanol (90 amu) and the loss of a silicon-linked methyl group to give [M - 15] ions are characteristic fragmentations for TMS derivatives.

The various compounds which were found to give a prominent ion from the trimethylsilyl rearrangement are listed in Table 1. The Table gives the abundance of the rearrangement ion $\left(\% \Sigma_{20}, 70 \mathrm{eV}\right)$ excluding the contributions from its isotope peaks. A large number of diastereomers were studied but since most of them exhibit small differences in the abundance of the rearrangement ion they have not been included in the Table. The $\mathrm{m} / \mathrm{e} 73$ peak from the trimethylsilyl ion is the base peak at $70 \mathrm{eV}$ for nearly all of the compounds in Table 1 , but the peak due to the rearrangement ion is among the five most intense peaks in most of the spectra.

The highest $\% \sum_{20}$-values for the $m / e 292$ ion according to Table 1 were obtained for the $C_{4}$ and $C_{5}$ acids. The lower values for the longer acids can be related to the increasing number of other favourable fragmentations. These have been described previously for aldonic and deoxyaldonic acids. ${ }^{2}$ The intensities are higher for the aldaric acids than for the corresponding aldonic and deoxyaldaric acids. This can be ascribed to the formation of the rearrangement ion from either end of the molecule for the aldaric acids. The abundant $m / e 292$ ion for tartronic acid demonstrates that the rearrangement also occurs when it involves the migration of a carboxyllinked TMS group and the loss of $\mathrm{CO}_{2}$ instead of an aldehyde.

The structure of the $m / e 292$ ion

To confirm the structural origin of the $m / e 292$ ion deuterium-labelled and substituted compounds were studied. 
TABLe 1. TRIMETHYLSILYLATED COMPOUNDS EXHIBITING PROMINENT PEAKS FROM tHe MCLAfFERTYTYPE TRIMETHYLSILYL REARRANGEMENT. MASS AND ABUNDANCE AT $70 \mathrm{eV}$ OF THE REARRANGEMENT IONS

\begin{tabular}{|c|c|c|c|}
\hline Compound & Derivative structure & $m / e$ & $\% \sum_{20} *$ \\
\hline \multicolumn{4}{|l|}{ Aldonic acids } \\
\hline Glyceric & $\begin{array}{c}\mathrm{TOCH}_{2}-\mathrm{CH}-\mathrm{COOT} \\
1 \\
\text { OT }\end{array}$ & 292 & $6 \cdot 0$ \\
\hline Erythronic & $\begin{array}{c}\mathrm{TOCH}_{2}-\mathrm{CH}-\mathrm{CH}-\mathrm{COOT} \\
1 \mid \frac{1}{\text { OT }} \text { OT }\end{array}$ & 292 & $8 \cdot 5$ \\
\hline Arabinonic & 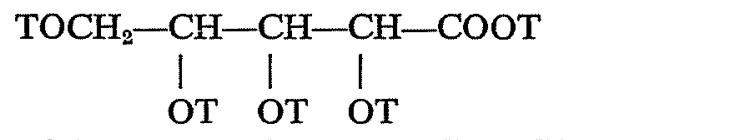 & 292 & $8 \cdot 8$ \\
\hline Gluconic & 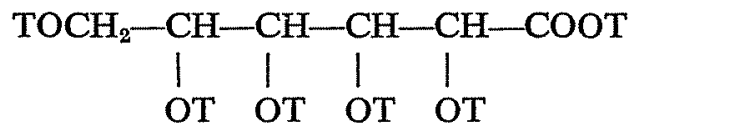 & 292 & $4 \cdot 5$ \\
\hline$D_{\text {-glycero-D-gulo-Heptonic }}$ & 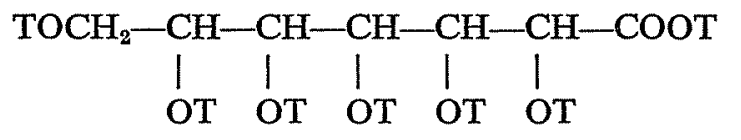 & 292 & $2 \cdot 8$ \\
\hline \multicolumn{4}{|l|}{ Deoxyaldonic acids } \\
\hline 4-Deoxythreonic & $\begin{array}{c}\mathrm{CH}_{3}-\mathrm{CH}-\mathrm{CH}-\mathrm{COOT} \\
\text { I } \\
\text { OT }\end{array}$ & 292 & $5 \cdot 7$ \\
\hline 6-Deoxygalactonic & 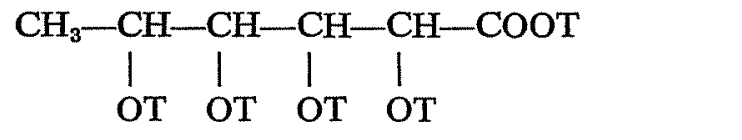 & 292 & $7 \cdot 1$ \\
\hline \multicolumn{4}{|l|}{ Aldaric acids } \\
\hline Tartronic & $\begin{array}{c}\text { TOOC-CH-COOT } \\
\text { OT }\end{array}$ & 292 & $6 \cdot 3$ \\
\hline Erythraric & 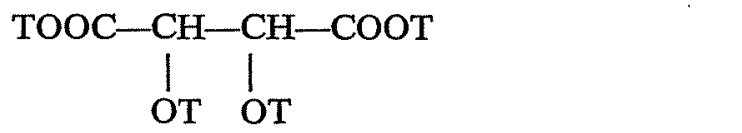 & 292 & $10 \cdot 3$ \\
\hline Arabinaric & 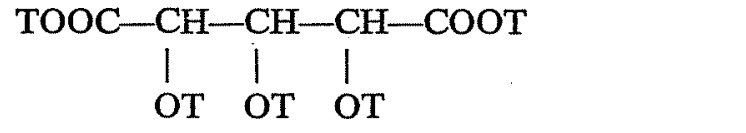 & 292 & $11 \cdot 7$ \\
\hline Glucaric & 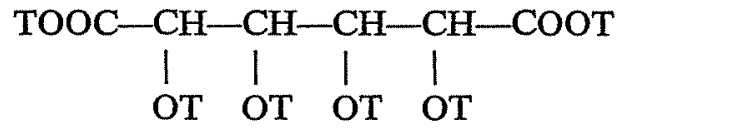 & 292 & $4 \cdot 9$ \\
\hline \multicolumn{4}{|l|}{ Deoxyaldaric acids } \\
\hline 2-Deoxy-erythro-pentaric & 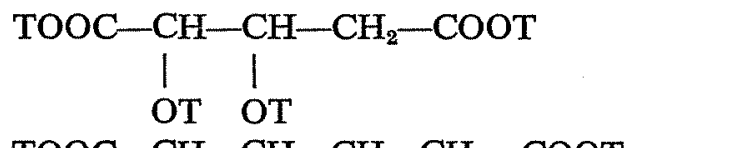 & 292 & $7 \cdot 1$ \\
\hline 2-Deoxy-arabino-hexaric & $\begin{array}{c}\text { TOOC }-\mathrm{CH}-\mathrm{CH}-\mathrm{CH}-\mathrm{CH}_{2}-\mathrm{COOT} \\
\mid \begin{array}{lll}\mid & \mid & \mid \\
\text { OT } & \text { OT } & \text { OT }\end{array}\end{array}$ & 292 & $3 \cdot 5$ \\
\hline 3-Deoxy-arabino-hexaric & 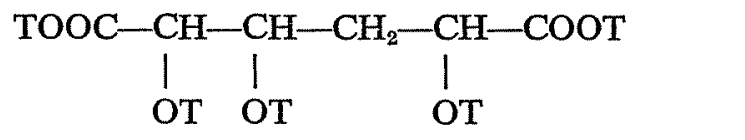 & 292 & $4 \cdot 4$ \\
\hline \multicolumn{4}{|l|}{ Branched acids } \\
\hline 2-C-Methylglyceric & $\begin{array}{c}\mathrm{TOCH}_{2}-\mathrm{C}\left(\mathrm{CH}_{3}\right)-\mathrm{COOT} \\
\text { OT }\end{array}$ & 306 & $1 \cdot 1$ \\
\hline
\end{tabular}


TABLE 1. (Continued).

\begin{tabular}{|c|c|c|c|}
\hline Compound & Derivative structure & $m / e$ & $\% \sum_{20} *$ \\
\hline 2-C-Methylribonic & 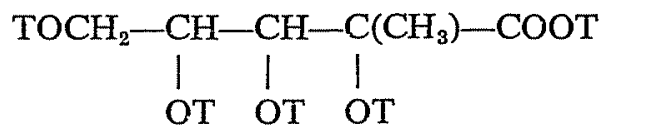 & 306 & $6 \cdot 6$ \\
\hline \multicolumn{4}{|l|}{ Methylated acids } \\
\hline Gluconic acid methyl ester & 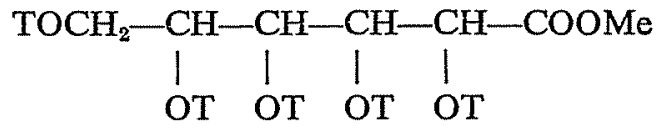 & 234 & $3 \cdot 8$ \\
\hline 2-O-Methylgluconic acid & 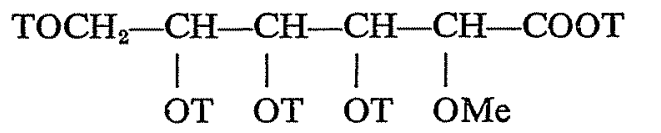 & 234 & $3 \cdot 6$ \\
\hline \multicolumn{4}{|l|}{ Acyclic ketoses } \\
\hline Tetrulose & $\begin{array}{c}\mathrm{TOCH}_{2}-\underset{\mathrm{OT}}{\mathrm{CH}}-\mathrm{CO}-\mathrm{CH}_{2} \mathrm{OT} \\
\text { oT }\end{array}$ & 306 & $1 \cdot 2$ \\
\hline erythro-Pentulose & 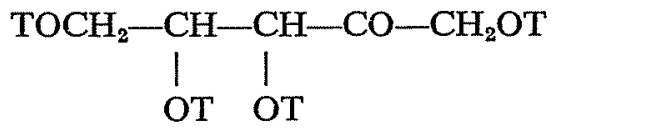 & 306 & $5 \cdot 2$ \\
\hline arabino-Hexulose & 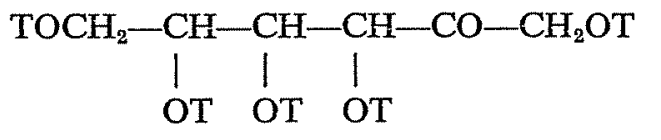 & 306 & $6 \cdot 5$ \\
\hline \multicolumn{4}{|l|}{ Lactones } \\
\hline $\begin{array}{l}\text { 3-Deoxy-2-C-hydroxymethyl- } \\
\text { tetrono-1,4-lactone }\end{array}$ & $\begin{array}{c}\mathrm{CH}_{2}-\mathrm{CH}_{2}-\mathrm{C}(\mathrm{OT})-\mathrm{CO} \\
! \\
\mathrm{CH}_{2} \mathrm{OT}\end{array}$ & 246 & $10 \cdot 1$ \\
\hline $\begin{array}{l}\text { 3-Deoxy-2-C-hydroxymethyl- } \\
\text { erythro-pentono-1,4-lactone }\end{array}$ & $\longrightarrow \mathrm{O}-$ & 348 & 8.9 \\
\hline & $\begin{array}{c}\mathrm{TOCH}_{2}-\mathrm{CH}-\mathrm{CH}_{2}-\mathrm{C}(\mathrm{OT})-\mathrm{CO} \\
\stackrel{\mid}{\mathrm{CH}_{2} \mathrm{OT}}\end{array}$ & & \\
\hline $\begin{array}{l}\text { Hydroxy keto acids } \\
\text { ribo-5-Hexulosonic acid }\end{array}$ & & & \\
\hline ribo-J-Hexulosonic acid & $\begin{array}{c}\mathrm{TOCH}_{2}-\mathrm{CO}-\mathrm{CH}-\mathrm{CH}-\mathrm{CH}-\mathrm{COOT} \\
\text { । } \\
\text { OT }\end{array}$ & $\begin{array}{l}292 \\
306\end{array}$ & $\begin{array}{l}2 \cdot 5 \\
3 \cdot 5\end{array}$ \\
\hline ribo-4-Hexulosonic acid & 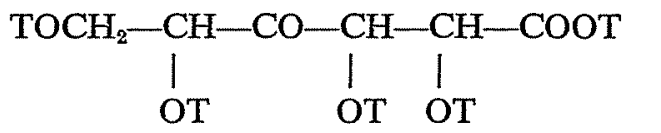 & 292 & $2 \cdot 3$ \\
\hline Dihydroxytartaric acid & 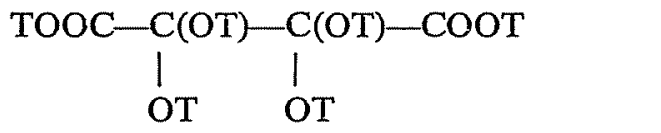 & 380 & $5 \cdot 0$ \\
\hline
\end{tabular}

* Peak intensity relative to the sum of the intensities of all peaks above $m / e 20$, greater than $1 \%$ of the base peak. Corrected for isotope peak contributions from ions of lower mass.

Spectra of $d_{9}$-TMS-labelled derivatives were recorded for gluconic, 4-deoxyerythronic, erythraric and glucaric acids. These spectra exhibit a peak at $\mathrm{m} / \mathrm{e} 319$ corresponding in intensity to the $m / e 292$ peak for the unlabelled derivatives. The shift of $27 \mathrm{amu}$ demonstrates that three intact TMS groups are incorporated in the ion.

The exchange of a TMS group which is unaffected by the rearrangement, for a 
methyl group, would be expected to have little influence on the formation of the rearrangement ion. To establish whether the ion contains the substituents linked to C-1 and C-2, methyl gluconate and 2-O-methylgluconic acid were prepared and their TMS derivatives investigated. The fragmentation patterns were similar to that of hexonic acids ${ }^{2}$ with expected mass shifts. Instead of the $m / e 292$ peak, peaks at $m / e 234$ (Table 1) were obtained in accordance with the mass difference between a TMS group and a methyl group. These mass shifts are strong evidence for the presence of the OTMS groups at C-1 and C-2 in the m/e 292 ion.

The introduction of a methyl group linked to $\mathrm{C}-2$ does not significantly alter the fragmentation paths for polyhydroxy acids with many strongly fragmentationdirecting groups. Accordingly 2-C-methylglyceric and 2-C-methylribonic acid ${ }^{2}$ exhibit abundant rearrangement ions (Table 1) of mass 306 instead of 292. This shift confirms that $\mathrm{C}-2$ and the hydrogen atom at $\mathrm{C}-2$ are a part of the structure of the rearrangement ion.<smiles>CO[CH][C+](OC)OC</smiles>

$m / e 234$

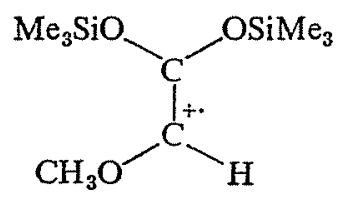

m/e 234

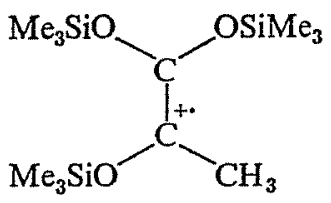

m/e 306

The results above imply that the carbonyl group is contained in the ion structure. Thus there is strong evidence that the $m / e 292$ ion contains the moiety on the ester side of the C-2 to C-3 bond together with an additional TMS group.

Potential acceptor sites for the migrating TMS group are the C-2 carbon atom and the three oxygen atoms. An electronically favourable structure of the rearrangement ion, consistent with its high abundance, is only obtained for migration to the carbonyl oxygen. The resulting $m / e 292$ ion acquires an unusually favourable structure from the extensive delocalization of both the positive charge and the unpaired electron over two carbon and three oxygen atoms and to some extent also over the three silicon atoms. Though preferred localization to the oxygen atoms would be expected all the rearrangement ions have been depicted as ionized olefins for convenience.

\section{Acyclic ketoses}

From its McLafferty character a rearrangement might be expected not only for $\alpha, \beta$-dihydroxy acids but also for acyclic $\alpha, \beta$-dihydroxy aldehydes and ketones. These TMS derivatives are not easily available since most aldoses and ketoses form cyclic glycoside derivatives but many ketoses were found to give a fairly large proportion of the acyclic form. The different derivatives from the sugars were separated in the gas chromatograph-mass spectrometer and the acyclic forms were identified from their characteristic and easily interpreted spectra.

Mass spectra of the open-chain derivatives were obtained for tetrulose, erythropentulose (ribulose) and arabino-hexulose (fructose). All of them exhibit peaks at m/e 306 (Table 1) from an abundant odd-electron ion. A metastable peak for tetrulose $\left(m^{*}=278\right.$ to $279 \cdot 5$; calc. $278 \cdot 7$ ) demonstrates its formation from the $m / e 336$ molecular ion. The anticipated trimethylsilyl rearrangement provides the obvious 
explanation for the formation of the $m / e 306$ ion. The structure is similar to that of the $m / e 292$ ion but only two OTMS groups are available for delocalization.

The $20 \mathrm{eV}$ spectrum of ribulose is given in Fig. 1 below those of ribonic and ribaric acids. The $m / e 306$ peak constitutes the base peak though it is less predominant than the $m / e 292$ peak for the acids. The peak at $m / e 234$ is consistent with a conventional McLafferty rearrangement. The most intense peaks remaining can be accounted for by the formation of ions from carbon chain cleavages.

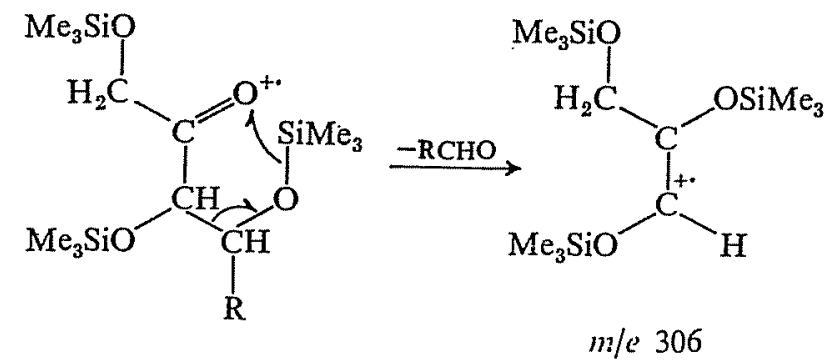

Spectra of both the non-cyclic form and the cyclic forms of TMS derivatives of fructose have been published and discussed earlier. ${ }^{5}$ The formation of the $m / e 306$ ion was ascribed to a hydrogen rearrangement and the ion was suggested to be identical with the ionized olefinic moiety from the McLafferty rearrangement. This interpretation is not consistent with the formation of the same ion for tetrulose and pentuloses and is unlikely in view of the evidence given in this paper.

\section{Lactones}

The carbonyl group in lactones is another potential acceptor site for the migrating TMS group but the rearrangement is blocked for unbranched acids because of the cyclic structure of the lactones. This is not the case with some C-2-branched acids of which 3-deoxy-2-C-(hydroxymethyl)tetronic acid and the two diastereomeric 3deoxy-2-C-(hydroxymethyl)pentonic acids were available for this study.

Very abundant $[\mathrm{M}-30]$ ions were obtained for the 1,4-lactones of these acids (Table 1) which is consistent with the investigated fragmentation reaction. In this case a non-planar transition state and a cyclic rearrangement ion closely related to the $m / e 292$ ion are implied.

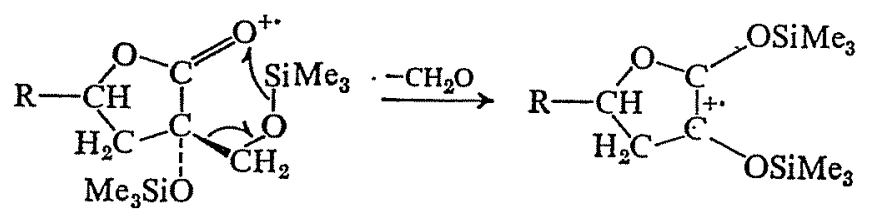

In a study of the $d_{9}$-TMS derivative of the $\mathrm{C}_{6}$ erythro isomer the corresponding peak was also obtained at [M - 30] in accordance with the loss of formaldehyde. The formation of the rearrangement ion from the molecular ion was supported by metastable peaks both for the unlabelled derivatives of the $\mathrm{C}_{6}$ lactones $(\mathrm{m} / \mathrm{e} 378 \rightarrow$ $m / e 348 ; m^{*}=320$ to $321 \cdot 5$; calc. $320 \cdot 4$ ) and for the $d_{9}$-TMS-labelled derivative $(m / e) 405 \rightarrow m / e ~ 375 ; m^{*}=346 \cdot 5$ to $348 \cdot 5$; calc. $\left.347 \cdot 2\right)$.

The predominance of the [M-30] ion is illustrated in Fig. 2 for the $20 \mathrm{eV}$ spectrum of the $\mathrm{C}_{5}$ lactone. Its formation by the alternative loss of $\mathrm{CH}_{2} \mathrm{O}$ from the lactone ring is unlikely because of the similar relative abundance of the $[\mathrm{M}-30]$ ion for the $\mathrm{C}_{6}$ acids. The rearrangement ion stands out as particularly prominent 


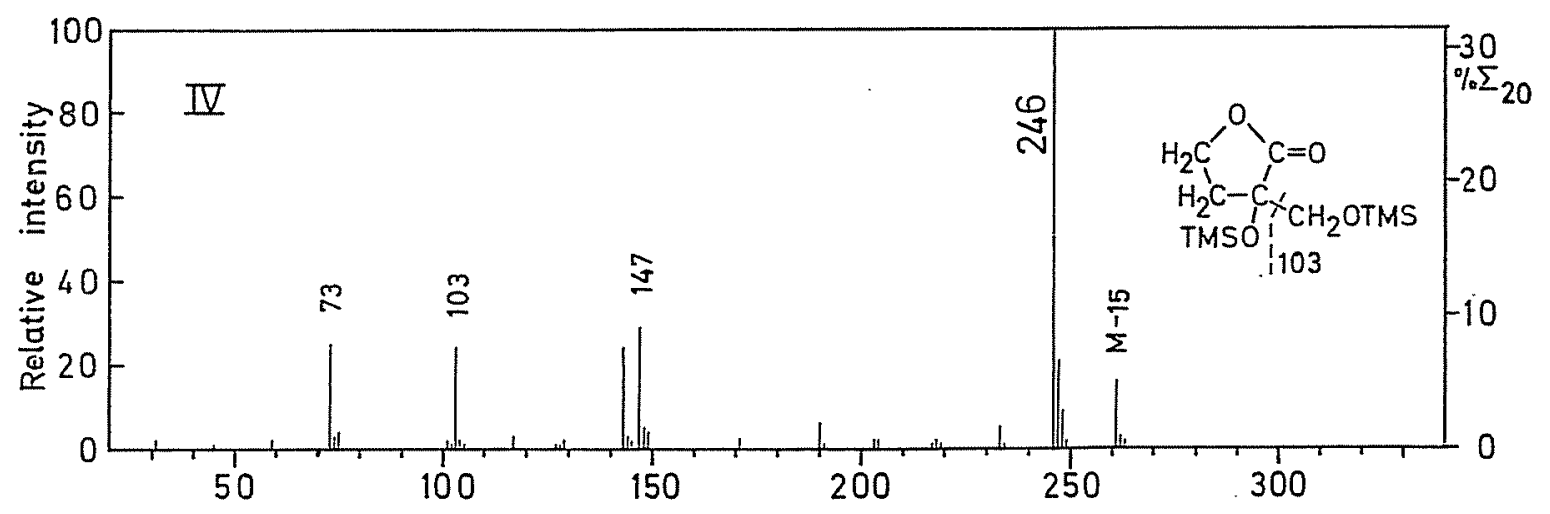

FIG. 2. Mass spectrum at $20 \mathrm{eV}$ of the TMS derivative of 3-deoxy-2-C-(hydroxymethyl)tetrono-1,4-lactone (IV).

for the lactones because other fragmentations are more unfavourable for the lactones than for the acyclic compounds. For the same reason the $m / e ~ 73$ and $m / e 147$ ions, characteristic of high electron energy spectra of TMS derivatives, are unusually abundant in the $20 \mathrm{eV}$ spectrum of the $\mathrm{C}_{5}$ lactone.

\section{Hydroxy keto acids}

Hydroxy keto acids are particularly interesting because their structure includes two carbonyl groups inducing the formation of different rearrangement ions. The four diastereomeric 5-hexulosonic acids and ribo-4-hexulosonic acid were studied. TMS derivatives were prepared to give almost exclusively the acyclic derivatives. The spectrum of ribo-5-hexulosonic acid is given in Fig. 3 as the upper spectrum.

Abundant rearrangement ions of masses 292 and 306 were obtained. These are to be expected from the ester portion and the keto portion of the molecule in accordance with the results above for 2,3-dihydroxy acids and acyclic ketoses. The higher abundance of the $m / e 306$ ion despite its less favourable structure may be ascribed to the lower ionization potential of the keto carbonyl group compared with the ester carbonyl group.

The spectrum of the $d_{9}$-TMS derivative of the same acid is given below that of the unlabelled derivative. Both peaks from the rearrangements are shifted $27 \mathrm{amu}$ to $\mathrm{m} / \mathrm{e} 319$ and $\mathrm{m} / \mathrm{e} 333$ confirming the inclusion of three TMS groups in theion structures.

The peak at $m / e 333$ is the base peak at $20 \mathrm{eV}$ for the 5-hexulosonic acids. A metastable peak $(m *=261.5$ to 263 ; calc. $262 \cdot 1)$ indicates formation of the $\mathrm{m} / \mathrm{e} 333$ ions from the chain cleavage ions of mass 423 by the elimination of trimethylsilanol. The $m / e 277$ ion is formed from the $m / e 321$ ion by rearrangement loss of $\mathrm{CO}_{2}$ for the 5-hexulosonic acids as well as several other acids, e.g. pentaric acids (Fig. 1). This fragmentation is also supported by a metastable peak $\left(m^{*}=\right.$ 238.5 to 240 ; calc. $239 \cdot 0$ ). The small peak at $m / e 234$ should be due to the conventional McLafferty rearrangement. The metastable transitions as well as the ion compositions indicated are supported by the appropriate metastable peaks and mass shifts in the spectrum of the $d_{9}$-TMS derivative.

The only abundant odd-electron ion for the 4-hexulosonic acid, compatible with the rearrangement of a TMS group, is that of mass 292 (Table 1) to be expected from its 2,3-dihydroxy acid structure. 


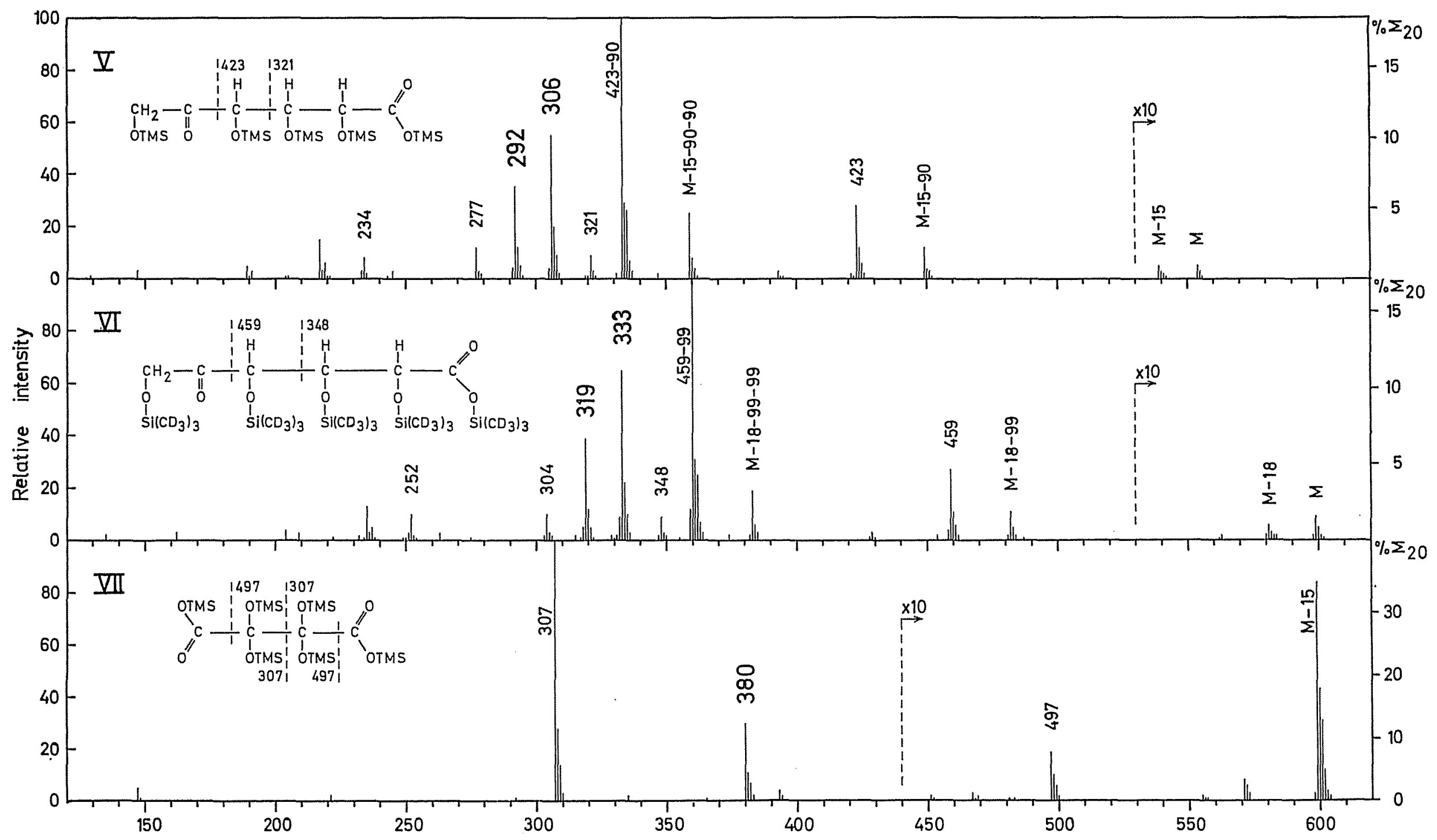

FIG. 3. Mass spectra at $20 \mathrm{eV}$ of the TMS (V) and $d_{0}$-TMS (VI) derivatives of ribo-5-hexulosonic acid and the TMS derivative of dihydroxytartaric acid (VII). 


\section{Rearrangement ions of low abundance}

For some $\alpha, \beta$-dihydroxy carbonyl compounds the expected rearrangement ions were absent or exhibited a low abundance. These cases are of interest both in the study of the rearrangement and in applications for structural analysis.

Three $\alpha, \alpha^{\prime}, \beta, \beta^{\prime}$-tetrahydroxy carbonyl compounds were studied and found to exhibit low intensities for the expected peaks from the rearrangement. The species were the erythro and threo isomers of 3-pentulose $\left(\mathrm{R}_{1}=\mathrm{R}_{2}=\mathrm{H}\right)$ and ribo-4-hexulosonic acid $\left(\mathrm{R}_{1}=\mathrm{H} ; \mathrm{R}_{2}=\right.$ COOTMS).<smiles>[R]OC([R3])C(O[Si])C(=O)C(O[Si])C([R])O[Si]</smiles>

Distinct peaks for the 3-pentuloses ascribed to the rearrangement ion were obtained at $\mathrm{m} / \mathrm{e}$ 408. Small metastable peaks were observed in the $70 \mathrm{eV}$ spectra confirming the formation of the ion by the loss of $\mathrm{CH}_{2} \mathrm{O}$ from the molecular ion $\left(m^{*}=379 \cdot 5\right.$ to 381 ; calc. 380-1). The abundance of the $m / e 408$ ion was very low, however, $(0 \cdot 2$ to $0.3 \%$ Rel. int.; $<0.1 \% \sum_{20}$ ) despite its predicted formation from both ends of the molecule.

For the 4-hexulosonic acid a small but distinct peak at $m / e 408$ was only observed when the electron energy was lowered to $15 \mathrm{eV}$. At higher electron energies it was obscured by isotope peaks from an $m / e 407$ ion. An [M - 30] peak from the anticipated migration to the keto group was not observed.

The acyclic derivatives of 3-deoxy-2-C-(hydroxymethyl)aldonic acids would be expected to rearrange like the lactones of the same acids discussed above. Significant peaks of the appropriate mass [ $\mathrm{M}-30]$ were obtained and corresponding [ $\mathrm{M}-30]$ peaks for the $d_{9}$-TMS derivative of the erythro isomer of the $\mathrm{C}_{6}$ acid support the predicted formation of the ions by the loss of $\mathrm{CH}_{2} \mathrm{O}$. Compared with the lactones the abundance of the ions was very low for the $\mathrm{C}_{5}$ acid $\left(2.5 \%\right.$ Rel. int.; $\left.0.3 \% \sum_{20}\right)$ as well as the two $\mathrm{C}_{6}$ acids $\left(0.2\right.$ to $0.3 \%$ Rel. int.; $\left.0.1 \% \Sigma_{20}\right)$. Spectra at $70 \mathrm{eV}$ of the $\mathrm{C}_{5}$ acid and one $\mathrm{C}_{6}$ acid were reproduced in the previous study of deoxyaldonic acids. ${ }^{2}$

An anomalously low abundance of the rearrangement ion may result from factors affecting the frequency of its formation e.g. steric effects. A low abundance may also be due to further decomposition of the ion. An apparent characteristic distinguishing the ions discussed in this paragraph from those previously described is that their decomposition by allylic C-C-cleavage is structurally feasible. Even-electron ions of mass 305 of no other obvious origin were observed for the compounds discussed. Decompositions of ions from the conventional McLafiferty rearrangement by favourable allylic cleavages are known. ${ }^{1}$ Thus although no decisive evidence was obtained further fragmentation is likely to explain, at least in part, the low abundance of some rearrangement ions. The high abundance of the $\mathrm{m} / \mathrm{e} 306$ ions from ketoses does not contradict this conclusion since allylic $\mathrm{C}$-O-Cleavages are energetically less favourable.

It is clear that whereas most types of $\alpha, \beta$-dihydroxy carbonyl compounds exhibit 
an abundant rearrangement ion of a characteristic mass this is not true in the exceptional cases when the ion can decompose by a favourable allylic $\mathrm{C}-\mathrm{C}$-cleavage.

Different $\alpha$-substituents. Dihydroxytartaric acid

From the structure of the rearrangement ion, $\alpha$-substituents with differing electronic effects would be expected to strongly infiuence its free energy and consequently its abundance. Some spectra of compounds with different substituents at $\mathrm{C}-2$ were therefore compared. The spectrum of dihydroxytartaric acid given in Fig. 3 is of special interest in this respect.

An intense peak at $m / e 380$ was obtained (Táble 1) in accordance with the anticipated rearrangement. The rearrangement ion acquires a symmetrical structure

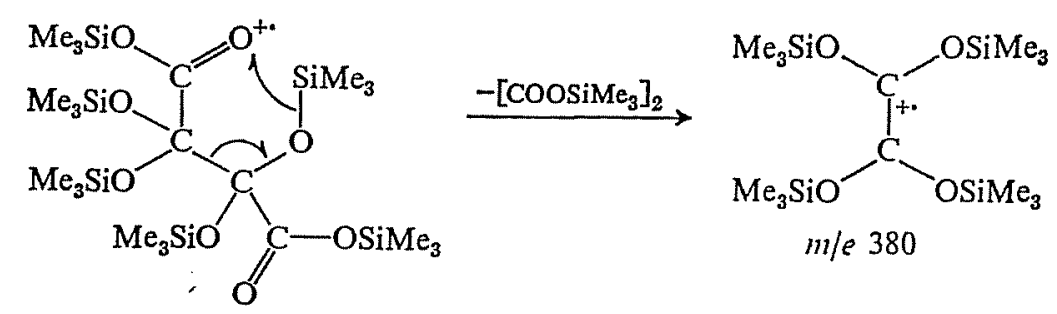

with delocalization over four OTMS groups compared to only three for the $m / e 292$ ion. The high abundance in spite of steric strains in the transition state as well as in the ion itself should be a result of the high resonance energy.

Partial formation of an m/e 307 ion from the m/e 380 ion by allylic $\mathrm{C}-\mathrm{O}-$ cleavage is not excluded, but presumably the base peak at $m / e 307$ is due primarily to ions formed by a cleavage of the $\mathrm{C}-2$ to $\mathrm{C}-3$ bond. The simplicity of the spectrum as a whole is partly explained by the unusual structure with no hydrogen atoms linked to the carbon skeleton.

For 3-hydroxy acids the analogue of the $m / e 292$ ion is an ion of mass 204 with no heteroatom at C-2. For comparable acids the abundance of this ion was found to be much lower than that of the m/e 292 ion in accordance with the less favourable resonance stabilization. The $\% \Sigma_{20}$-value for the $m / e 204$ ions was lower than 0.5 for the previously published ${ }^{2}$ spectra of 3-hydroxypropionic acid (cf. 6.0 for $m / e 292$ from glyceric acid) and 3,4-dihydroxybutyric acid ( $c f .8 .5$ for $\mathrm{m} / \mathrm{e} 292$ from erythronic acid) as well as for malic acid (cf. 10.3 for $m / e 292$ from erythraric acid and 5.0 for $m / e ~ 380$ from dihydroxytartaric acid).

The observed dependence of the abundance on the nature of the $\alpha$-substituents is further evidence that the structure assigned to the rearrangement ion is correct. The results also indicate that rough predictions of the influence of different $\alpha$-substituents on the abundance can be made.

Exchange of an OTMS group at C-2 for an NHTMS group is unlikely to affect the rearrangement very much because of the similar mesomeric and inductive effects of these groups. The abundant $m / e 291$ ion observed for threonine and the McLaffertytype rearrangement proposed for its formation ${ }^{4}$ are therefore consistent with the results given in this paper.

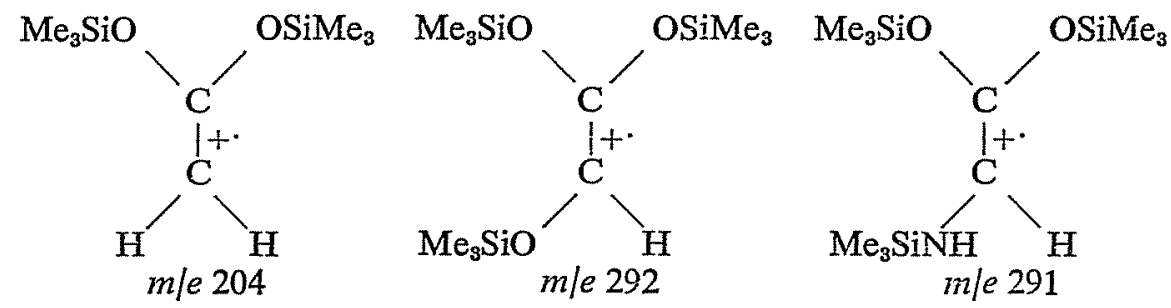


Site specificity for the migrating group

A characteristic feature of the McLafferty rearrangement is the specific origin of the migrating hydrogen atom from the $\gamma$-position. The trimethylsilyl rearrangement must occur through a similar six-membered ring for a number of compounds in this study, e.g. glyceric acid, 4-deoxytetronic acids, tartronic acid and tetrulose because only one TMS group is available for the migration. Further potential migrating TMS groups do not drastically increase the abundance of the rearrangement ion (Table 1). The spectra ${ }^{2}$ of 3-deoxyaldonic acids exhibit $m / e 292$ peaks of low intensity $\left(<1 \% \sum_{20}\right)$. These observations indicate preferential migration from the $\beta$-OTMS group and the rearrangement has been depicted accordingly in all the previous fragmentation schemes.

In order to get a more complete picture of the specificity of the rearrangement a number of methylated derivatives were studied. The exchange of a TMS group for a methyl group should have little influence on the fragmentation with the exception that methyl groups do not rearrange. For 3-O-methylgulonic acid the abundance of the m/e 292 ion was found to be $2 \cdot 7 \% \sum_{20}\left(c f .4 \cdot 5 \% \sum_{20}\right.$ for gluconic acid in Table 1) and for 2,3-di-O-methylxylonic acid the value for the $m / e 234$ ion was $2 \cdot 6 \% \Sigma_{20}$ (cf. arabinonic acid). 3-O-Methyl-lyxo-5-hexulosonic acid (cf. ribo-5-hexulosonic acid) gave rise to moderately abundant ions of masses $292\left(1.7 \% \sum_{20}\right)$ and 306 $\left(1 \cdot 2 \% \sum_{20}\right)$ though neither can be formed through a six-membered ring. Although these results are compatible with preferred migration from a $\beta$-OTMS group they demonstrate that migrations through larger rings can occur to a considerable extent. In applications for structure determination this means that the presence of a peak due to the rearrangement cannot be taken as a definite proof of the presence of a $\beta$-OTMS group.

In contrast to $3-\mathrm{O}$-methylgulonic acid, the $m / e 292$ peak is small $\left(<0.5 \% \sum_{20}\right)$ for 3,5,6-tri-O-methylgluconic acid. This indicates that migration from the $\gamma$-OTMS group is not necessarily the second most favourable alternative after migration from the $\beta$-OTMS group. Probably the free energy of the neutral products formed governs the position of the migrating group to some extent. The formation of a neutral carbonyl moiety is likely to contribute to the preference for migration through a six-membered ring. The fact that the TMS groups are linked to oxygen instead of carbon is also likely to affect the specificity.

Long-range migrations of a TMS group to a carbonyl group resulting in oddelectron ions have been reported earlier. The formation of the $m / e 204$ ion, discussed in the previous paragraph, or its methyl ester analogue of mass 146 was demonstrated for some dicarboxylic ${ }^{6}$ and hydroxycarboxylic ${ }^{6,7}$ acids.

\section{The nature of the migrating group}

The McLafferty rearrangement is usually formulated as involving the migration of a hydrogen radical ${ }^{1}$ in preference to a proton. The schemes above imply the analogous migration of a trimethylsilyl radical to the initially ionized carbonyl group. An anionic character of the migrating group is unlikely because of the polarity of the $\mathrm{Si}-\mathrm{O}$ bond but rearrangement of a trimethylsilyl cation after initial charge localization at the migrating TMS group is a conceivable alternative formulation. The ability of electron-deficient silicon to develop a fifth bond should facilitate the attack from an electron pair and lead to a favourable transition state. The generally higher migratory 
aptitude of trimethylsilyl groups compared to alkyl groups can also be associated with the pentavalent character of silicon.

The specificity for the conventional McLafferty rearrangement has been ascribed to the directional effect of the unpaired electron in the carbonyl group. The lower specificity observed for the trimethylsilyl rearrangement may be associated with an increased cationic character of the migrating moiety.

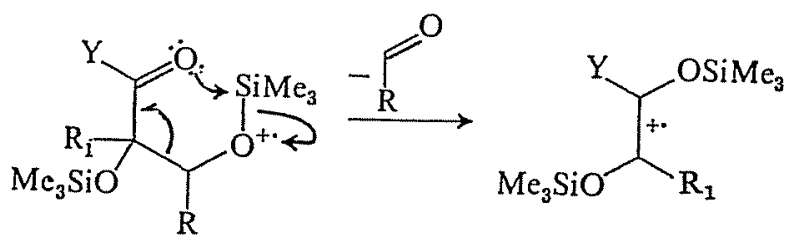

\section{Dependence of abundance on configuration}

The free energy differences for the molecular ion as well as the rearrangement ion should be small for most diastereomers. In contrast considerable configurationdependent interactions are anticipated in the postulated six-membered activated complex. Newman projections along the $\beta-\mathrm{C}$ to $\alpha-\mathrm{C}$ bond in the planar transition state for the erythro and threo isomers of an $\alpha, \beta$-dihydroxy carbonyl compound are illustrative. It is evident that the steric strain from the eclipsed interactions is greater for the threo than for the erythro isomer if a bulky $\mathrm{R}$ group is linked to $\mathrm{C}-3$. The

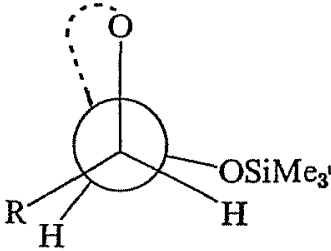

erythro

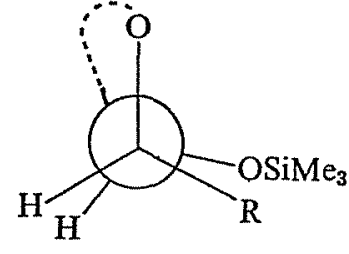

threo

resulting difference in the free energy of activation is likely to affect the abundance of the rearrangement ion for the two isomers.

Compounds forming rearrangement ions of high abundance are best suited for a study of the relationship between abundance and configuration since most other fragmentations may be dependent on configuration as well. The tetraric and pentaric acids were chosen for the purpose. The spectra of the pentaric acids were recorded in succession under carefully controlled conditions to minimize errors.

The abundance of the $m / e 292$ ion for the tetraric acids was $10 \cdot 3 \% \sum_{20}$ for the erythro and $8.4 \% \sum_{20}$ for the threo isomer. For the pentaric acids the calculated values for the same ion were $12 \cdot 3 \% \sum_{20}$ for ribaric acid (erythro, erythro), $11 \cdot 7 \% \sum_{20}$ for arabinaric acid (erythro, threo), and $11 \cdot 2 \% \sum_{20}$ for xylaric acid (threo, threo). These results are consistent with the predicted effect of configuration when both ends of the acids are considered.

No similar systematic relationship was found for the rearrangement ions from the four 5-hexulosonic acids studied. More strongly configuration-dependent fragmentations are likely to cancel such relationships for many of the compounds investigated. The results for the tetraric and pentaric acids demonstrate that the abundance of the rearrangement ion depends on the configuration, however, and consequently that mass spectrometry may be sensitive to configuration even for acyclic diastereomers. 
Separate ionic and radical sites

In a previous paragraph the absence of stabilizing groups at $\mathrm{C}-2$ was shown to hamper the investigated rearrangement.

The formation of abundant ( 1 to $4 \% \Sigma_{20}$ ) odd-electron ions of mass 306 for 2deoxypentonic, 2-deoxyhexonic and 2,6-dideoxyhexonic acids ${ }^{2}$ indicates another significant rearrangement for these acids. A shift from $\mathrm{m} / \mathrm{e} 306$ to $\mathrm{m} / \mathrm{e} 333$ for the $d_{9}$-TMS derivative of 2-deoxy-erythro-pentonic acid demonstrates that the ion retains three TMS groups. An obvious explanation is a rearrangement which is similar to the McLafferty-type rearrangement but involves cleavage of the C-3 to $\mathrm{C}-4$ bond. The transfer of a trimethylsilyl group may be represented as involving

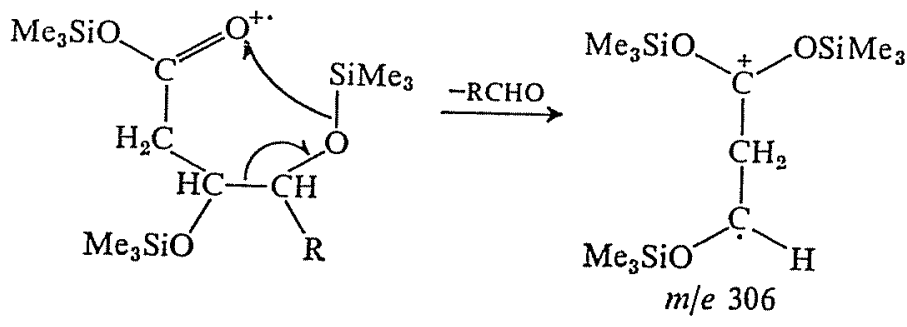

either a radical or a cation. In the resulting ion the positive charge and the unpaired electron are separated by a methylene group but both are effectively delocalized.

Evidence for the formation of analogous ions which have the charge and radical sites separated by a chain of methylene groups has been given for esters of fatty acids with two vicinal OTMS groups. ${ }^{8}$ The rearrangement is clearly of interest in the structural analysis of polyhydroxy carbonyl compounds lacking $\alpha$-substituents. No analogous ions were observed for the compounds with an $\alpha$-OTMS group which is consistent with the more favourable features of the competing McLafferty-type rearrangement.

\section{Influence of electron energy}

As already mentioned the relative abundance of the ions from the trimethylsilyl rearrangement was found to increase at lower electron energies. The difference between $20 \mathrm{eV}$ and $70 \mathrm{eV}$ spectra is illustrated by a comparison of the $\% \sum_{20}$-values in Figs. 1 to 3 and those in Table 1. Values at four selected ionizing voltages are given in Table 2 for ions from ribonic acid and ribulose.

The variation for the characteristic $m / e 292$ and $m / e 306$ ions is similar and representative for the ions produced in the rearrangement. The relative intensity is

Table 2. Dependence of Relative abundance $\left(\% \sum_{20}\right)$ of Different types of IONS ON ELECTRON ENERGY

\begin{tabular}{lrrrrr}
\hline & $m / e$ & $70 \mathrm{eV}$ & $30 \mathrm{eV}$ & $20 \mathrm{eV}$ & $15 \mathrm{eV}$ \\
\hline Ribonic acid & 292 & $10 \cdot 3$ & $20 \cdot 0$ & $31 \cdot 1$ & $41 \cdot 0$ \\
& 73 & $20 \cdot 7$ & $6 \cdot 4$ & $1 \cdot 2$ & $1 \cdot 7$ \\
& 147 & $7 \cdot 1$ & $3 \cdot 8$ & $1 \cdot 0$ & $0 \cdot 7$ \\
& 511 & $0 \cdot 6$ & $0 \cdot 9$ & $1 \cdot 5$ & $2 \cdot 5$ \\
& 307 & $3 \cdot 5$ & $5 \cdot 8$ & $9 \cdot 2$ & $12 \cdot 2$ \\
Ribulose & 103 & $6 \cdot 4$ & $7 \cdot 9$ & $3 \cdot 7$ & $0 \cdot 5$ \\
& 217 & $4 \cdot 5$ & $6 \cdot 4$ & $5 \cdot 5$ & $2 \cdot 8$ \\
& 306 & $5 \cdot 2$ & $9 \cdot 8$ & $16 \cdot 2$ & $21 \cdot 5$ \\
& 234 & $3 \cdot 1$ & $6 \cdot 1$ & $10 \cdot 0$ & $14 \cdot 5$ \\
\hline
\end{tabular}


markedly increased at the lowest electron energies. The high relative abundance of these and other structure-specific ions demonstrates the usefulness of low electron energy spectra in structural analysis.

For comparison, a number of other characteristic ions are included in Table 2. The trimethylsiliconium $(\mathrm{m} / \mathrm{e}$ 73) and pentamethyldisiloxonium $(\mathrm{m} / \mathrm{e}$ 147) ions are formed in multistep fragmentations requiring a high internal energy and exhibit a strong and characteristic dependence on electron energy opposite to that of the McLafferty-type rearrangement ions. The data for the [M - 15] ions ( $\mathrm{m} / \mathrm{e} 511$ for ribonic acid) and the $m / e 307$ ions from chain cleavage (Fig. 1) are explained by the promotion of the further decomposition of these ions by high electron energies. The $m / e 103$ and $m / e 217$ [307 - 90] ions are intermediate in nature. The variation for the $m / e 234$ ion from the McLafferty rearrangement for ribulose is very similar to that of the $m / e 306$ and $m / e 292$ ions.

The increased abundance at low electron energies of the conventional McLafferty rearrangement ion is explained by the low frequency factor of the fragmentation. ${ }^{9}$ A similar frequency factor is predicted for an analogous migration of a trimethylsilyl group and the observed dependence on electron energy is therefore consistent with the McLafferty character of the rearrangement.

\section{Competition with the conventional McLafferty rearrangement}

Most of the investigated compounds with the structure required for the trimethylsilyl rearrangement have $\gamma$-hydrogen atoms available for the McLafferty rearrangement. The result is a competition for the same acceptor site between the two rearrangements.

For the hydrogen rearrangement $m / e 220$ and $m / e 234$ ions are equivalents to the $m / e 292$ ion from 2,3-dihydroxy acids and the $m / e 306$ ion from acyclic ketoses. Abundant $m / e 220$ ions were obtained in the $70 \mathrm{eV}$ spectra of erythronic $\left(5 \cdot 1 \% \sum_{20}\right)$, 4-deoxythreonic $\left(2 \cdot 7 \% \sum_{20}\right)$ and 2-deoxy-erythro-pentaric $\left(2.8 \% \sum_{20}\right)$ acids, as well as in those of their diastereomers. A mass shift to $m / e 238$ for the $d_{9}$-TMS derivative of 4-deoxy-erythronic acid confirms that the ion contains two TMS groups. An abundant $m / e 234$ ion $\left(3 \cdot 1 \% \sum_{20}\right)$ was only obtained for ribulose ( $c f$. Fig. 1). A small $\left(<0.5 \% \sum_{20}\right)$ but distinct peak at m/e 234 for ribo-5-hexulosonic acid is shifted to $m / e 252$ for the $d_{9}$-TMS derivative ( $c f$. Fig. 3 ) in accordance with the proposed structure. Fragmentations other than the McLafferty rearrangement explaining the observed $m / e 220$ and $m / e 234$ peaks are difficult to visualize.

A striking feature of the compounds exhibiting abundant ions attributed to the hydrogen rearrangement is that at least two $\gamma$-hydrogen atoms are available. A decrease in steric strains both in the transition state and the predicted olefinic product is likely to favour the fragmentation for these compounds.

For all species studied the hydrogen rearrangement produces ions of lower abundance than the competing trimethylsilyl rearrangement. At $70 \mathrm{eV}$ the majority

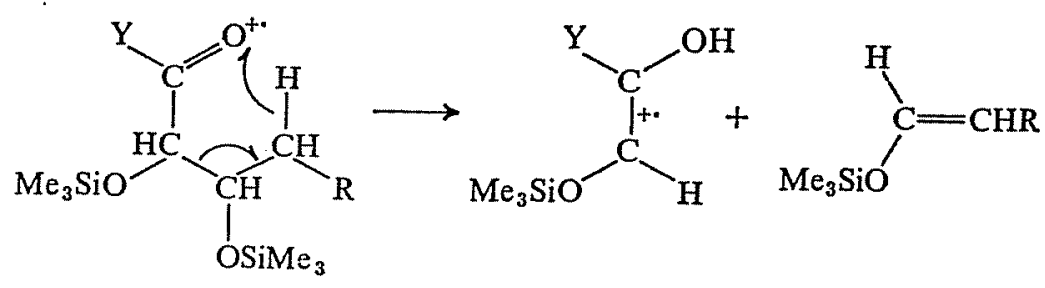


of the compounds studied exhibit no distinct peaks at all from the hydrogen rearrangement. These observations emphasize further the significance and the unusually favourable character of the investigated trimethylsilyl rearrangement.

\section{EXPERIMENTAL}

Most of the compounds were either commercial or prepared in previously published or current works in this department. The aldonic and deoxyaldonic acids were those recently studied by mass spectrometry. ${ }^{2} \quad \mathrm{C}_{5}$ and $\mathrm{C}_{6}$ aldaric and deoxyaldaric acids were prepared by nitric acid oxidation. ${ }^{10}$ Tetrulose was obtained by isomerization of erythrose in pyridine and the 3-pentuloses by oxidation of pentitols. ${ }^{11}$ Isomerization of hexuronic acids ${ }^{12}$ yielded 5-hexulosonic acids and ribo-4-hexulosonic acid. Similarly 3-O-methyl-lyxo-5-hexulosonic acid was obtained from 4-O-methylglucuronic acid. 3-O-Methylgulonic acid was prepared by borohydride reduction of 4-O-methylglucuronic acid. ${ }^{13}$ The 2-O-methylgluconic and 2,3-di-O-methylxylonic acids were produced by bromine oxidation of 2-O-methylglucose and 2,3-di-O-methylxylose. 3,5,6-Tri-O-methylgluconic acid was kindly supplied by Dr. M. H. B. Hayes, Birmingham.

The methyl ester of gluconic acid was prepared from calcium gluconate $(20 \mathrm{mg})$ in dry methanol $(20 \mathrm{ml})$ with ion exchange resin added $\left(5 \mathrm{ml}, 50-100\right.$ mesh, Dowex $50 \mathrm{~W}-\mathrm{X} 8 \mathrm{in}[\mathrm{H}]^{+}$form, preconditioned with methanol). The mixture was kept at $50^{\circ} \mathrm{C}$ for $40 \mathrm{hrs}$. and subsequently the resin was removed by filtering and methanol by evaporation.

The TMS derivatives were prepared with bis(trimethylsilyl)acetamide (BSA) or bis(trimethylsilyl)triffuoroacetamide (BSTFA) in dry pyridine. In most cases trimethylchlorosilane (TMCS) was added to assist the reaction. The proportion of the acyclic form of the keto compounds was increased by the exclusive use of BSA or BSTFA. Acyclic derivatives of lactone-forming acids were produced from salts of the acids. The $d_{9}$-TMS derivatives were prepared with $d_{18}$-BSA (Merck, Sharp and Dohme of Canada Ltd) in pyridine. Shaking of the reaction mixtures for a few hours at room temperature effected complete silylation in all instances.

The mass spectra were obtained from a LKB 9000 gas chromatograph-mass spectrometer. The samples ( 1 to $10 \mu \mathrm{g}$ of each TMS derivative) were introduced through a QF-1 column ( $3 \mathrm{~m} ; 3 \%$ DC QF-1 on 100 to 120 mesh Gas Chrom Q). This column also effected separation of the compounds obtained in mixtures with derivatives of a different structure. The column temperatures (100 to $190^{\circ} \mathrm{C}$ ) were chosen to give 5 to 10 mins. retention time. Mass spectral data were: temperature of molecule separator 200 to $220^{\circ} \mathrm{C}$, temperature of ion source $270^{\circ} \mathrm{C}$, accelerating voltage $3.5 \mathrm{kV}$, trap current $60 \mu \mathrm{A}$, exit slit $0.05 \mathrm{~mm}$, collector slit $0.10 \mathrm{~mm}$, scanning time ( $/ e 15$ to 800$) c a .5 \mathrm{sec}$.

Acknowledgements-The author is indebted to the Swedish Board for Technical Development for financial support.

\section{REFERENCES}

1. H. Budzikiewicz, C. Djerassi and D. H. Williams, Interpretation of Mass Spectra of Organic Compounds, Holden-Day, San Francisco, 1967, pp. 155 to 162.

2. G. Petersson, Tetrahedron 26, 3413 (1970).

3. W. P. Weber, R. A. Felix and A. K. Willard, J. Am. Chem. Soc. 92, 1420 (1970).

4. W. J. A. VandenHeuvel, J. L. Smith and J. S. Cohen, J. Chromatog. Sci. 8, 567 (1970).

5. H.-CH. Curtius, M. Müller and J. A. Völlmin, J. Chromatog. 37, 216 (1968).

6. G. H. Draffan, R. N. Stillwell and J. A. McCloskey, Org. Mass Spectrom. 1, 669 (1968).

7. G. Eglinton, D. H. Hunneman and A. McCormick, Org. Mass Spectrom. 1, 593 (1968).

8. P. Capella and C. M. Zorzut, Anal. Chem. 40, 1458 (1968).

9. D. H. Williams and R. G. Cooks, Chem. Commun. 663 (1968).

10. L. Jansén and O. Samuelson, J. Chromatog. 57, 353 (1971).

11. J. Havlicek, G. Petersson and O. Samuelson, Acta Chem. Scand. in press.

12. B. Carlsson and O. Samuelson, Carbohydrate Res. 11, 347 (1969).

13. E. R. Nelson, P. F. Nelson and O. Samuelson, Acta Chem. Scand. 22, 691 (1968). 